\title{
SEGURANÇA JURÍDICA E CERTEZA DO DIREITO EM MATÉRIA DISCIPLINAR - ASPECTOS ATUAIS*
}

\author{
ELIEZER PEREIRA MARTINS**
}

I - Introdução; II - Estado de direito (pressuposto político da segurança e da certeza do direito); III - Distinção entre segurança jurídica e certeza do direito; IV - Segurança jurídica, certeza do direito e Justiça; V Elementos formais integradores da segurança jurídica; VI - Segurança jurídica, certeza do direito e direito públicos subjetivos; VII - Segurança jurídica e certeza no direito administrativo; VIII - Direito administrativo disciplinar e seu estágio atual; IX - Patogenias do direito e do processo disciplinar e sua conexão com a segurança e a certeza do direito; $X-$ Conclusões.

\section{I - Introdução.}

O desafio que se põe no presente esforço de pesquisa, é verificar se concorrem no campo administrativo disciplinar hodierno, a segurança jurídica e a certeza do direito na medida para que se alcance a Justiça na matéria.

A inexistência ou o baixo grau de atuação dos institutos e preceitos que expressam a segurança jurídica e a certeza do direito, tornam o direito disciplinar apenas e tão-somente um instrumento iníquo de dominação burocrática, contribuindo para a indisciplina, desordem e horror nas coisas da Administração Pública.

Somente o sistema disciplinar concebido e aplicado segundo os cânones da segurança jurídica e da certeza, afina-se com os valores do Estado de direito, sendo este o sistema disciplinar a ser desenvolvido e aprimorado pelos hermeneutas e aplicadores do direito disciplinar.

* Exposição proferido no III Congresso Nacional de Direito Disciplinar promovido pelo Centro Ibero-Americano de Administração e Direito em 18 de Junho de 2002 em Brasília-DF.

** Especialista em direito público, Mestre em direito administrativo, Advogado, sócio-gerente da Pereira Martins Advogados Associados, Professor de direito administrativo em cursos preparatórios para as carreiras da Magistratura e do Ministério Público, parecerista e assessor jurídico municipal.

R. Dir. Adm.,

Rio de Janeiro, 230: 141-152, Out./Dez. 2002 
No século XVIII. a expressão "Estado de direito" designava a administração interna do Estado ou ciência da polícia, compreendendo as finanças, a economia pública e privada, o comércio, a estatística e matérias políticas e jurídicas. O Estado de direito da época tinha por objetivo principal o bem comum ou felicidade da vida, a segurança e a prosperidade do Estado, de acordo com os ditames da política ou arte do governo.

Na segunda metade do século XIX veio à luz a concepção de Estado de direito, vinculado ao contexto de idéias políticas então existentes.

Estado de direito é, portanto, o Estado que submete seus atos em relação aos cidadãos, às decisões judiciárias. O Estado de direito é aquele que reconhece os direitos individuais, cuidando de acatar e fazer cumprir o direito por ele mesmo instituído.

O Estado em consideração segue a linha do direito, se auto-limitando, protegendo as liberdades individuais, contrapondo-se ao estado de poder, ou totalitário, sendo constitucionalmente organizado.

Os dois fundamentos do Estado de Direito são a segurança e a certeza jurídica.

A segurança e a certeza do direito são indispensáveis para que haja justiça, porque é óbvio que na desordem não é possível reconhecer direitos ou exigir o cumprimento de obrigações.

\section{III - Distinção entre segurança jurídica e certeza do direito}

Segundo Carlos Aurélio Mota de Souza: “... Segurança é fato, é o direito como 'factum visivel', concreto, que se vê..."'

A segurança se traduz objetivamente (Direito objetivo a priori), através das normas e instituições do sistema jurídico (como a norma agendi dos romanos). Já a certeza do direito (como um posterius se forma intelectivamente nos destinatários destas normas e instituições (a facultas agendi, embora esta analogia não seja completa). ${ }^{2}$... "Desta forma, a Segurança objetiva das leis dá ao cidadão a Certeza subjetiva das ações justas, segundo o Direito." 3

Assim, fala-se em certeza do direito quando o sistema tende a abolir lacunas da lei, obscuridades, complicação dos dispositivos legais, excesso de legislação, a demora nos julgamentos, o direito livre como forma de instabilidade, a mutabilidade ou a multiplicidade indiscriminada das leis.

1 SOUZA, Carlos Aurélio Mota de. Segurança jurídica e jurisprudência - Um enfoque filosófico-jurídico. São Paulo: Ltr, 1996, p. 25.

2 Idem. p. 27.

3 Ibidem p. 27. 
A segurança e a certeza do direito são necessárias para que haja justiça - como já demonstramos - porque é óbvio que na desordem não é possível reconhecer direitos ou exigir o cumprimento de obrigações.

Segundo Carlos Aurélio Mota de Souza: "Segurança e Justiça, portanto não se contrapõem, mas enquanto esta é um poder moral, desarmado, sua garantia de efetivação no direito repousa na materialdiade objetiva da segurança jurídica."4

Acima da segurança está sempre, como valor supremo, a justiça, não sendo de repetir-se com apoio a frase de Goethe: "Prefiro uma injustiça à desordem", como têm feito vários desses autores, porque revela um profundo egoísmo burguês, um medo das transformações sociais e prega um conformismo inadmissível. Radbruch sustentou em 1932 que a segurança está acima da justiça, mas depois que viu os horrores do nazismo, pregou a volta ao direito natural, reconhecendo que a injustiça é sempre injustiça, ainda que apresentada sob a forma de uma lei. ${ }^{5}$

\section{$V$ - Elementos formais integradores da segurança jurídica}

Formalmente a segurança jurídica é assegurada pelos princípios seguintes ${ }^{6}$ : irretroatividade da lei, coisa julgada, respeito aos direitos adquiridos, respeito ao ato jurídico perfeito, outorga de ampla defesa e contraditório aos acusados em geral, ficção do conhecimento obrigatório da lei, prévia lei para a configuração de crimes e transgressões e cominação de penas, declarações de direitos e garantias individuais, justiça social, devido processo legal, independência do Poder Judiciário, vedação de tribunais de exceção, vedação de julgamentos parciais etc.

\section{$V I$ - Segurança juridica, certeza do direito e direitos públicos subjetivos}

Segundo Leib Soibelman ${ }^{7}$, como decorrência natural da adoção do Estado de direito, resulta que tanto o Estado, quanto os indivíduos são sujeitos de direitos subjetivos de natureza pública: Estado e indivíduo exigem-se reciprocamente o cumprimento de obrigações e prestações que leis de direito positivo estabelecem a favor de um e de outro.

Hartmut Maurer afirma que: "Les droits subjectifs peuvent être fondés aussi bien sur le droit privé quer sur le droit public. II s'agit ici de ces derniers. Le droit public subjectif est, par conséquent - du point de vue du citoyen - le pouvoir

4 SOUZA, Carlos Aurélio Mota de. Segurança jurídica e jurisprudência - Um enfoque filosófico-jurídico. São Paulo: Ltr, 1996. p. 269.

5 SOIBELMAN. Leib. Enciclopédia jurídica. Elfez. Ediçāo em CD-ROM.

6 SOIBELMAN. Leib. Enciclopédia jurídica. Elfez. Edição em CD-ROM.

7 Idem. Edição em CD-Rom. 
juridique conféré par le droit public à un individu d'exiger de l'État, en vue de poursuivre la satisfaction de ses propes intérêts, un comportement déteminé. "8

Ora, dizer que o Estado e o indivíduo devem acatar o direito positivo é o mesmo que se afirmar o princípio da segurança jurídica numa via de duas mãos.

Subjetivamente os direitos públicos se manifestam pela faculdade de um ou outro (Estado e indivíduo) invocarem a lei em seu favor para exigir da outra parte uma conduta a que têm direito (leia-se certeza do direito). Não existe Estado de direito sem o reconhecimento de direitos públicos subjetivos. Eles constituem também uma grande garantia para as liberdades públicas, porque implicam no reconhecimento pelo Estado da eminente dignidade da pessoa humana do cidadão.

Jellinek classificou ${ }^{9}$ os direitos públicos subjetivos em quatro categorias os status subjectionis, libertatis, civitatis e activae civitatis.

Santi Romano divide esses direitos em: a) direitos de supremacia, b) direitos de liberdade, c) direito cívicos, d) direitos políticos, e) direitos públicos patrimoniais.

Sílvio Longhi apresenta outra classificação: a) direitos de liberdade (status libertatis), estado negativo, obrigação de não fazer do Estado; b) direitos cívicos (status civitatis), prestação positiva do Estado; c) direitos políticos, incluindo os eleitorais: d) estados de sujeição ou dependência (status subjectionis), que não admitem o exercício pelo indivíduo de nenhum direito contra o Estado.

Em resumo, pode-se afirmar que a segurança jurídica e a certeza do direito integram o acervo do direito público subjetivo exigível de parte-a-parte entre indivíduo e Estado.

\section{VII - Segurança jurídica e certeza no direito administrativo}

É cediço que o direito é uno. Decorre daí que o direito administrativo, como ramo da ciência jurídica posto num Estado de direito, há que se preordenar aos fatos caracterizadores da segurança jurídica e aos valores exteriorizadores da noção subjetiva de certeza do direito.

Rafael Entrena Cuesta afirma que: “...Si la división de poderes constituye el presupuesto político para la existencia del Derecho administrativo, el Estado de Derecho debe considerarse como um pressuposto jurídico. El nuicleo central de aquél etá constituido, en efecto, por las normas que regulan las relaciones entre la Administración y los particulares, y estas normas sólo adquiren carácter jurídico externo, ya que eran dictados por el principe para la buena marcha de la Administración, a él sometida, y portanto, si bien vinculaban a los órganos subordinados,

8 MAURER, Harmut. Droit administratif allemand. Paris: Librairie Générale de Droit et de Jurisprudence, 1994. p. 156.

9 As classificações mencionadas foram extraidas da obra de Leib Soibelman com remissão de Castro Nunes, Teoria e prática do poder judiciário. Ver. For. Rio. 1943; R. Carré de Malberg. Teoria general del Estado. Fondo de Cultura. México, 1948. 
carecian de eficacia en cuanto al mismo príncipe; por lo que no constituian garantía para los ciudadanos." 10

Embora no plano teórico seja quase intuitiva a aceitação da segurança jurídica e da certeza do direito, no plano da realidade o direito administrativo pátrio afasta-se destes institutos, como veremos pormenorizadamente adiante.

\section{VIII - Direito administrativo disciplinar e seu estágio atual}

Grande salto experimentou o direito administrativo em sua vertente disciplinar com o advento do Estado democrático de direito em nosso país.

O principal ícone da evolução referida está na processualdiade decorrente da inserção da ampla defesa e do contraditório como garantias fundamentais aos acusados no processo disciplinar.

Sem embargo do aperfeiçoamento da disciplina, há ainda preconceitos e atecnias a obnubilar a plenitude da matéria disciplinar, que pressupõe, à evidência, acatamento incondicional aos fundamentos do Estado de Direito.

IX - Patogenias do direito e do processo disciplinar e sua conexão com a segurança e a certeza do direito

\subsection{O problema}

Várias "moléstias" acometem o direito e o processo administrativo disciplinares.

Todas estas "doenças" podem ser enquadradas como vulnerações da segurança ou da certeza do direito, como passaremos a descrever.

\subsection{A concepção reducionista do legislador em matéria disciplinar}

Salvo honrosas exceções, a maioria das normas disciplinares em vigor nos diversos entes e órgãos das pessoas políticas pátrias, considera, por vezes subrepticiamente, a sanção e o processo disciplinares de somenos importância.

Há um preconceito posto no sentido de que os bens-interesse relativos ao status funcional são de menor importância, resultando daí um menoscabo, uma certa indiferença posta na lei acerca dos direitos dos agentes públicos submetido ao processo disciplinar.

Exemplo desta postura é a difusão do "princípio do informalismo" no campo do processo disciplinar, esta fórmula na verdade escamoteia a indiferença e a des-

10 CUESTA, Rafael Entrena. Curso de derecho administrativo. 11. ed. Madrid: Tecnos, 1995, p. 44. 
consideração pelos bens-interesses sujeitos à sanção disciplinar, possibilitando aos déspotas de plantão a aplicação do sistema disciplinar ao sabor de suas paixões.

Em verdade, não há sanção disciplinar, repreensão verbal que seja, que uma vez registrada nos assentamentos funcionais do agente público que não the cause prejuízos de grande expressão (retardo da promoção, óbices a benefícios, impossibilidade de remoção, acúmulo de faltas para fins demissórios etc.).

Recorde-se que hodiernamente, a pena demissória acaba por ter carga punitiva, na maioria das vezes, superior às sanções penais, mormente em face do laxismo reinante em matéria de execução penal. Assim, não é incomum o agente público increpado temer com maior intensidade a sanção disciplinar à sanção penal.

Ora, a concepção reducionista da sanção disciplinar e seu processo é vulneradora da segurança jurídica, em especial porque autoriza a desconsideração ao institutos da prévia lei para a configuração de transgressões e cominação de penas, permite a quebra da irretroatividade da lei, diminui a expressão da ampla defesa e contraditório no processo disciplinar, desconsidera as declarações de direitos e garantias individuais, e o devido processo legal.

Em suma, a concepção reducionista da matéria disciplinar acaba por vulnerar quase todos os elementos caracterizadores da segurança jurídica, gerando assim para os atores do processo disciplinar contexto de incerteza do direito.

De outra parte, por conta da visão reducionista, o legislador se vale no campo disciplinar, em larga escala, de conceitos jurídicos indeterminados e de disposições de baixo grau de vinculação, soluções que atingem a certeza do direito na matéria.

\subsection{A concepção reducionista do aplicador em matéria disciplinar}

Se é certo que a concepção reducionista é encampada pelo legislador com maior autoridade e intensidade dela se vale o aplicador do sistema disciplinar, utilizando-se desta concepção para fins menores e espúrios.

Agrega-se à concepção reducionista, potencializando-a, o despreparo técnico da autoridade administrativa competente em matéria disciplinar, e, de forma ainda mais deletéria, a sua má fé, que lhe permite valer-se do sistema disciplinar para perseguir, para favorecer, enfim para dar azo às paixões, preconceitos e idiossincrasias que grassam na Administração, quebrando por completo as expectativas decorrentes da entronização dos valores da segurança e certeza do direito.

\subsection{Da descontinuidade da difusão da processualidade administrativa, segundo os valores da segurança e da certeza do direito}

De início é necessário ter-se em consideração que o sopro da processulidade e da teoria que lhe dá supedâneo não se fez sentir em todos os entes e órgãos públicos dos diversos níveis políticos com a mesma intensidade e com a uniformidade desejada. Assim é que, em muitos rincões do país, mormente na administração pública 
municipal e militar. ainda se pune com fundamento na malfadada "verdade sabida" ou, o que é pior, sem processo.

Deste modo, se é certo que em alguns entes e órgãos públicos o processo administrativo disciplinar, superando todos os óbices de que tratamos neste tópico, aproxima-se em maior ou menor grau de segurança e da certeza do direito, na maioria deles porém, nada há que permita inferir-se a existência destes fatos e valores no processo de que tratamos.

\subsection{Concepção autoritária e a presunção da culpa do acusado}

A matriz do sistema disciplinar é por natureza autoritária. Assim, quer o legislador, quer o administrador incumbido da aplicação do sistema disciplinar, tomam o increpado por culpado, anes mesmo da redação da portaria inaugural do processo disciplinar.

Assim, os processos administrativos disciplinares na maioria das vezes não se instauram para apurar uma transgressão disciplinar, mas sim para punir-se aquele que se toma por culpado.

Prova do fenômeno aqui descrito é o fato de que, no plano legislativo a maioria dos "regulamentos disciplinares", ao cuidarem da fundamentação da decisão disciplinar, traçam apenas hipóteses ensejadoras de responsabilização, passando ao largo das excluentes da antijuridicidade, da absolvição por insuficiência de provas, por inexistência do fato ou negativa de autoria.

Em outras palavras, os regulamentos disciplinares esmeram-se nas hipóteses de responsabilização, deixando de instrumentar o aplicador para a "improvável" hipótese do acusado ser inocente.

Há portanto, em matéria disciplinar, iníqua e dissimulada inversão do ônus da prova que se dá no plano das entrelinhas das normas disciplinares e da dialética das "apurações" na matéria.

Assim, não há certeza do direito para aquele que se vê processado no plano disciplinar, posto que é considerado adrede culpado.

\subsection{Concepção perfunctória da ampla defesa e do contraditório em matéria disciplinar}

Mercê dos preconceitos é vícios a que nos referimos nas linhas anteriores e, em especial pela má fé, presunção de culpa e despreparo técnico dos órgãos incumbidos da aplicação do sistema disciplinar, o direito de ampla defesa e contraditório encontra-se, quando aplicado em matéria disciplinar, acolhido como mera providência de mero expediente (perfunctória).

Em outras palavras, a contragosto defere-se a defesa, mas desconsidera-se por completo seu conteúdo, quer pela intenção deliberada de punir, quer pela ausência de preparo técnico das autoridades responsáveis pela aplicação das normas discipli- 
nares que, na maioria das vezes, não têm a mínima noção do sentido e significado da ampla defesa e do contraditório.

Como já aduzimos, grande salto deu a matéria disciplinar com a redação dada ao inciso LV do art. $5^{\circ}$ da Constituição da República, ao prestigiar-se como garantia individual a ampla defesa e o contraditório nos processos disciplinares. Porém, embora se tenha garantido tai direitos subjetivos públicos, no plano da concretude não logrou a legislação infraconstitucional e a Administração dar-lhes efetividade, de tal sorte que no estágio atual a ampla defesa e o contraditório são formalidades vazias de mero rito processual.

Tal olvido é também expressão do reducionismo a que nos referimos acima.

Assim resta demonstrado que a ampla defesa e o contraditório em matéria disciplinar foram "dadas com uma mão" pelo legislador constituinte orignário e "tiradas como a outra" pela inépcia da legislador infraconstitucional.

Assim, podemos afirmar que resta prejudicada a segurança jurídica em matéria disciplinar posto que a ampla defesa e o contraditório não se opeacionalizaram na plenitude, do que resulta a incerteza do direito na matéria.

\subsection{Admissibilidade de auto-defesa e defesa por leigos nos processos disciplinares}

$O$ inciso I do art. $1^{\circ}$ a Lei $n^{\circ} 8.906$, de 04 de julho de 1994 , que dispõe sobre - Estatuto da Advocacia e a Ordem dos Advogados do Brasil-OAB, estabeleceu serem atividades privativas de advocacia a postulação a qualquer órgão do Poder Judiciário e aos juizados especiais, pondo de lado a postulação no plano dos processos administrativos de natureza conenciosa, a exemplo dos processos disciplinares.

$\mathrm{Na}$ esteira da lacuna deixada pelo Estatuto da Advocacia, e mesmo antes dela, mas no mesmo sentido, normas regentes do processo disciplinar dos multifários órgão e entes públicos dos diversos níveis políticos admitem a auto-defesa e o patrocínio de defesa implementado por leigos.

Sendo certo que no mais das vezes os agentes públicos são hipossuficientes para constituirem advogados (sobretudo especialistas) nos processos disciplinares em que sejam acusados, e, dada a inépcia do Estado-acusador em suprir-lhe tal direito, passou-se a admitir a defesa implementada pelo próprio acusado ou por pessoa por ele indicada, mesmo que sem formação técnica, sendo certo que na prática agentes públicos, também subordinados à autoridade acusadora, passaram a "patrocinar" as defesas necessárias à perfunctoriedade do processo.

Ora, não bastasse a insuficiência técnica de defensor leigo, agrega-se ainda ao fenômeno aqui considerado as limitações hierárquicas deste defensor que submetido à autoridade disciplinar, tal qual o acusado, não pode agir com a independência e energia necessárias a uma defesa eficiente no plano disciplinar.

Defesa técnica é elemento necessário e inafastável da ampla defesa. Defesa promovida por leigo é o mesmo que ausência de defesa. Assim, a solução da defesa implementada por leigos em processos disciplinares inviabiliza o grau de segurança jurídica necessários ao aperfeiçoamento do Estado de direito e da Justiça. 


\subsection{Atipicidade em matéria disciplinar (técnica das transgressões não especificadas)}

Ainda há, embora abertamente inconstitucionais, normas e regulamentos disciplinares que prestigiam a sanção a condutas "não especificadas".

Sob esta atecnia, abre-se ensanchas à interpretação equivocada de que a sanção disciplinar pode ser aplicada sem respeito à adequação típica.

Ora, a responsabilização disciplinar em sede de conduta "não especificada" transforma o administrador em legislador, podendo este, livre e arbitrariamente, definir o que é, e o que não é permitido ou proibido.

Ora, um dos elementos formais da segurança jurídica é a prévia lei para a configuração de crimes e transgressões. Note-se que esta garantia não se restringe à matéria penal, como pode parecer num primeiro momento, visto que a segurança jurídica e a certeza do direito são direitos subjetivos públicos também aplicáveis aos agentes públicos acusados, que uma vez privados da prévia ciência do que é permitido ou proibido, acabam reflexamente privados da segurança e da certeza o direito.

Destarte, o acolhimento da técnica das trangressões "não especificadas" nega vigência à segurança e a certeza do direito, e por via de consequiência ao próprio Estado de direito.

\subsection{Parcialidade (tendenciosidade) estrutural do processo administrativo disciplinar}

Outro fator a limitar, senão a obstar a segurança jurídica e a certeza do direito em matéria disciplinar, junge-se à parcialidade estrutural dos sujeitos processuais.

Não há no processo disciplinar a observância da parêmia "Juditium est actus trium personarum: judicis, actoris et rei." 11

No processo administrativo disciplinar, um dos sujeitos parciais da relação jurídica processual (Administração-acusadora),fala em nome e no interesse do sujeito imparcial da relação (Administração-julgadora) e vice-e-versa.

Assim, no mais das vezes a cognição do sujeito imparcial é ab ovo contaminada, posto que o sujeito imparcial é o mesmo sujeito parcial que se pronuncia num momento diverso do processo.

Ajunte-se à limitação estrutural referida, as relações de hierarquia próprias do órgão e do ente público, que tornam o processo disciplinar um jogo de "cartas marcadas", já que no mais das vezes a autoridade ou órgão subordinado competente para instruir o processo, fá-lo de modo a dar cumprimento ao comando de apuração que, na verdade, encerra substancialmente uma decisão condenatória, que não é senão o juízo do sujeito imparcial projetado no início da relação processual disciplinar (comando inaugural do feito).

11 Diziam as Ordenações Filipinas (livro $3^{\circ}$, título 20, proêmio): “Três pessoas são por direito necessárias em qualquer Juizo, Juiz que julgue, autor que demande, e réu que se defenda". 
Assim, a parcialidade estrutural do processo administrativo disciplinar acaba por fulminar a segurança jurídica por possibilitar julgamentos parciais.

\subsection{Acatamento da teoria da intangibilidade do mérito administrativo}

Ainda, e lamentavelmente, é firme a jurisprudência no sentido de que em se tratando de processo administrativo disciplinar, compete ao Poder Judiciário apreciar a regularidade do procedimento, à luz dos princípios do contraditório, da ampla defesa e do devido processo legal, sem, contudo, adentrar no mérito administrativo.

Trata-se da vetusta e facista teoria da intangibilidade do mérito administrativo, cujas conclusões negam abertamente o disposto no inciso XXXV do art. $5^{\circ}$ da Constituição da República.

Entende-se assim a anulação do ato administrativo, pelo Poder Judiciário, só é possível, quando ele se mostra ilegal, ou ilegítimo. Presentes os requisitos formais, indispensáveis à sua existência e eficácia, não pode ser desconstituído pelo Judiciário, ao qual, não cabe perquirir seu mérito administrativo, pois só à Administração compete valorar-lhe os motivos e escolher-lhe o objeto, quando autorizada a decidir sobre sua conveniência e oportunidade.

Do entendimento sufragado resulta a possibilidade de quebra da segurança jurídica e da certeza do direito, posto que sob o manto da legalidade (com outorga de ampla defesa e contraditório, sob o sequenciamento imposto pelo due process of law), pode-se editar ato disciplinar sem suporte nas provas coligidas nos autos do processo.

\subsection{Insuficiência técnica das comissões processantes e autoridades disciplinares em geral}

Por conta dos princípios erigidos pelos incisos LIV e LV do artigo $5^{\circ} \mathrm{da}$ Constituição da República (devido processo legal e ampla defesa e contraditório), pode-se afirmar que o processo administrativo disciplinar passou a compartilhar dos princípios da teoria geral do processo.

A partir do marco considerado é certo que os processos administrativos disciplinares somente poderão expressar Justiça por meio de condução técnica balizada pelos cânones da teoria geral do processo.

Sem embargos da correção da assertiva supra-mencionada, em larga parcela dos órgãos e entes da Administração Pública o processo administrativo disciplinar é conduzido e decidido por autoridades administrativas sem nenhuma formação técnico-jurídica.

Poder-se-ia dizer que a insuficiência de que aqui se trata pode ser superada com a manifestação ou acompanhamento da procuradoria do ente ou órgão. Ora, todos aqueles que conhecem a Administração em seus embates intestinos bem o sabem que nem sempre a procuradoria é próxima ou interessada na correção técnica do processo disciplinar, havendo até mesmo órgãos de procuradoria submetidos hierarquicamente à vontade contaminada do hierarca. 
Destarte, a insuficiência técnica das comissões processantes e autoridades disciplinares em geral acaba por reduzir a zero a certeza do direito, visto sua incapacidade de abolir lacunas da lei, obscuridades, complicação dos dispositivos legais, a demora nos julgamentos e o direito livre como forma de instabilidade.

\subsection{Emprego do sistema disciplinar para fins de implementação de politica de redução de quadros e despesas}

Uma das maiores perversões em sede de matéria disciplinar é o emprego das sanções administrativas para implementação de política de pessoal tendente à redução dos quadros do ente ou órgão.

Como a sanção disciplinar demissória, nos diversos regimes de contratação admitidos em nosso regime, não enseja indenização de verbas rescisórias, vem se ampliando no país o emprego da via disciplinar para fins de redução dos quadros de pessoal.

À evidência, para viabilizar o desvio de finalidade aqui considerado as autoridades competentes fulminam os fatos caracerizadores da segurnaça jurídica e os valores da certeza do direito.

\subsection{Processo disciplinares trial by media}

É comum a influência da mídia na decisão de processos judiciais, não escapando a esta influência os processos disciplinares.

Tal influência opera de afogadilho e, no mais das vezes, "atropelando" a segurança jurídica e a certeza do direito fazendo do acusado presa indefesa daquilo que se decide ns redações dos órgãos de imprensa.

Os processos disciplinares cuja decisão se dá por força do trial by media vem se alargando na medida mesma do alargamento do poder da imprensa e da vulnerabilidade dos cargos da Administração Pública.

\section{$X-$ Conclusões}

O Estado de direito se auto-limita, protegendo as liberdades individuais, contrapondo-se ao estado de poder, ou totalitário, sendo constitucionalmente organizado.

Os dois fundamentos do Estado de Direito são a segurança e a certeza jurídica.

A segurança e a certeza do direito são indispensáveis para que haja justiça, porque é óbvio que na desordem não é possível reconhecer direitos ou exigir o cumprimento de obrigações.

A segurnça se traduz objetivamente (Direito objetivo a priori), através das normas e instituições do sistema jurídico (como a norma agendi dos romanos), Já a certeza do direito (como um posterius se forma intelectivamente nos destinatários destas normas e instituições (a facultas agendi, embora esta analogia não seja completa). 
Formalmente a segurança jurídica é assegurada pelos princípios seguintes: irretroatividade da lei, coisa julgada, respeito aos direitos adquiridos, respeito ao ato jurídico perfeito, outorga de ampla defesa e contraditório aos acusados em geral, ficção do conhecimento obrigatório da lei, prévia lei para a configuração de crimes e transgressões e cominação de penas, declarações de direitos e garantias individuais, justiça social, devido processo legal, independência do poder judiciário, vedação de tribunais de exceção, vedação de julgamentos parciais etc.

Pode-se afirmar que a segurança jurídica e a certeza do direito integram o acervo do direito público subjetivo exigível de parte-a-parte entre indivíduo e Estado.

O direito administrativo, como ramo da ciência jurídica posto num Estado de direito, há que se preordenar aos fatos caracterizadores da segurança jurídica e aos valores exteriorizadores da noção subjetiva de certeza do direito.

Sem embargo do aperfeiçoamento do direito disciplinar, há ainda preconceitos e atecnias a obnubilar a plenitude da matéria, eu pressupõe, a evidência, acatamento incondicional aos fundamentos do Estado de Direito.

Várias "moléstias" acometem o direito e o processo administrativo disciplinares.

Todas estas "doenças" podem ser enquadradas como vulnerações da segurança ou da certeza do direito, a exemplo da concepção reducionista do legislador em mátéria disciplinar; da concepção reducionista do aplicador em matéria disciplinar; da descontinuidade da difusão da processualidade administrativa, segundo os valores da segurança e da certeza do direito; na Concepção autoritária e a presunção da culpa do acusado; da concepção perfunctória da ampla defesa e do contraditório em matéria disciplinar; da admissibilidade de auto-defesa e defesa por leigos nos processos disciplinares. Atipicidade em matéria disciplinar (técnica das transgressões não especificadas); da parcialidade (tendenciosidade) estrutural do processo administrativo disciplinar; do acatamento da teoria da intangibilidade do mérito administrativo; da insuficiência técnica das comissões processantes e autoridades disciplinares em geral; do emprego do sistema disciplinar para fins de implementação de política de redução de quadros e despesas e dos processos disciplinares trial by media.

Em conclusão podemos afirmar que no estágio atual, a Justiça e o Estado de direito não se concretizaram na matéria disciplinar, pelos óbices à efetivação da segurança jurídica e da certeza do direito. 